\title{
DELIBERATION AND LEGITIMACY IN TRANSNATIONAL GOVERNANCE: THE CASE OF ENVIRONMENTAL IMPACT ASSESSMENTS
}

\author{
Neil Craik*
}

\begin{abstract}
This paper begins by recognising that transnational environmental governance structures have been the subject of criticism as lacking democratic legitimacy. The author suggests, however, that instead of using the traditional liberal view of democracy where decisions are made by majority agreement, deliberative democracy may provide a solution. This approach focuses not on the aggregation of fixed interests within a given territory but on a continual process of dialogue between decisionmakers and all those affected, a process of mutual justification by the exchange of reasons. The author examines the possible application of this theory, using environmental impact assessments carried out pursuant to environmental conventions as an example of the theory in practice. The author shows how a deliberative democratic approach brings a range of advantages to decisionmaking concerning cross-border environmental harm, concluding that this approach has the potential to enhance the legitimacy of environmental decision-making beyond the state.
\end{abstract}

\section{INTRODUCTION}

A prevailing preoccupation among theorists of globalisation is the relative absence of democratic institutions in the transnational sphere when compared with the domestic sphere. While the democratic credentials of transnational governance structures have been questioned most frequently in the context of international economic institutions, transnational environmental institutions have given rise to similar concerns. ${ }^{1}$ The emergence of legitimacy concerns is reflective of the changing nature of environmental governance structures that go beyond the nation state in an

* Faculty of Law, University of New Brunswick. The author gratefully acknowledges the generous support of the Social Sciences and Humanities Research Council of Canada (International Opportunities Fund).

1 Daniel Bodansky "The Legitimacy of International Governance: A Coming Challenge for International Environmental Law" (1999) 93 Am J Int'l L 596. See also, Stephen Bernstein "Legitimacy in Global Environmental Governance" (2005) 1 J Intl L \& Intl Rel 139. 
increasingly interdependent world. While states still hold a preeminent position in the regulation of environmental resources, they increasingly share this responsibility with a diffuse collection of governmental and non-governmental bodies. In terms of the institutional structure of environmental governance, the use of treaties as the primary mechanism for interstate cooperation is supplemented by less formal approaches to norm creation and implementation, such as trans-governmental networks, epistemic communities, and the extraterritorial application of domestic laws. Even where treaties do form the basis of environmental cooperation, the treaty structure may contemplate the development of rules and guidelines by subsidiary bodies, may delegate compliance and dispute resolution functions, and in the cases of some international organisations, may involve significant amounts of delegated decision-making. A principal source of the legitimacy crisis is that state consent as the conditio sine qua non of legitimate governance beyond the state is either unavailable or inadequate. As transnational environmental governance structures become more complex and affect more people, more directly, the lines of democratic accountability have become increasingly attenuated.

One promising line of inquiry that seeks to bridge the legitimacy gap in transnational environmental governance is deliberative democratic theory. What distinguishes deliberative democratic theory from other democratic theories is its emphasis on reciprocal justification as the principle basis for legitimacy. Whereas liberal (individualist) theories tend to emphasise the aggregation of fixed interests through voting or other consent-granting mechanisms, deliberative approaches emphasise the possibility of persuasion through reasoned and public forms of policy justification. Because deliberative democratic approaches require policy-makers to direct their justifications to those persons who are most affected by their decisions and account for the interests of those affected, deliberative approaches are well suited to the transnational character of many environmental governance structures. However, notwithstanding the theoretical promise of deliberative democracy to address legitimacy concerns arising from environmental governance beyond the state, it should be acknowledged that too little attention has been given to existing mechanisms within governance structures that may promote deliberative processes at the transnational level. ${ }^{2}$ Consequently, there is a need to examine the extent to which deliberative democracy can be put into operation within existing transnational environmental institutions as a working policy approach.

To this end, after examining the legitimacy challenges that are emerging in transnational governance structures and the suitability of deliberative democratic forms of governance to address those challenges, ${ }^{3}$ the third part of this paper considers the ability of international commitments to

2 Graham Smith Deliberative Democracy and the Environment (Routledge, New York, 2003) 6.

3 This paper presents a version of deliberate democracy developed by Amy Gutmann and Dennis Thompson. Their argument is most fully laid out in Amy Gutmann and Dennis Thompson Democracy and Disagreement: Why Moral Conflict Cannot Be Avoided in Politics, and What Should Be Done about It (The Belknap Press of Harvard University Press, Cambridge (Mass) 1996) [Democracy and Disagreement]. 
conduct environmental impact assessments (EIAs) to foster public, reasoned and discursive interactions between actors in the transnational sphere. EIA, as a mechanism to implement international environmental objectives, has been embraced by international policy-makers in a wide range of contexts, including transboundary pollution, biodiversity, climate change and marine pollution. While the central idea that animates the EIA process is that decisions affecting the environment should be made in light of a comprehensive understanding of their impacts, EIAs go beyond simply requiring the ex ante consideration of scientific issues by promoting an informationrich and participatory environment for agency decision-making. Moreover, notwithstanding their evaluative mandate, EIA commitments do not impose substantive obligations to avoid environmental harm. Rather the process is self-regulatory and reflexive, requiring decision-makers to account for and respond to the views of affected persons, and justify their decisions in light of their adherence to both right process and prevailing substantive environmental norms. EIAs, in effect, require decision-makers to engage affected persons in a principled and justificatory dialogue and can therefore be viewed as a mechanism to enhance accountability through deliberative practices.

Drawing on domestic and transnational examples of EIA processes, this paper seeks to contribute to the debate on the suitability of deliberative models of democracy in transnational environmental governance structures. It does so by demonstrating how an existing set of institutionalised decision-making processes controls interactions between transnational actors and contributes to accountability in transnational environmental decision-making.

\section{THE LEGITIMACY CHALLENGE IN TRANSNATIONAL ENVIRONMENTAL GOVERNANCE}

In 1999, Daniel Bodansky identified the lack of democratic credentials in international environmental governance structures as an emerging challenge. ${ }^{4}$ At the heart of Bodansky's analysis were legitimacy concerns precipitated by the shift away from environmental obligations being subject to the specific consent of states towards a more governance oriented structure relying on general consent and delegation of rule-making authority to international organisations and subsidiary treaty bodies. Developments in international environmental law in the intervening years have served to reinforce Bodansky's basic concern. For example, Bodansky notes two principal aspects of the emerging legitimacy problem: the move away from consensus decision-making within treaty structures and the increasingly direct effect of international rule-making on private actors. The trend towards majoritarian decision-making has continued under treaties such as the

However, the main points of their arguments are laid out in an accessible and shorter chapter in Amy Gutmann and Dennis Thompson Why Deliberative Democracy (Princeton University Press, Princeton, 2004) [Gutmann and Thompson]. Given the necessarily summary nature of the discussion of deliberate democracy in this article and given that my own arguments are aimed at a non-specialist (in political philosophy) audience, I have chosen to cite principally this shorter work.

4 Bodansky, above n 1. 
Cartagena Protocol ${ }^{5}$ and under the Kyoto Protocol. ${ }^{6}$ Delegations such as these raise legitimacy concerns where states are bound against their will in ways that could not be easily predicted at the time consent to the delegation was given, as is the case with the broad plenary powers granted to the Conference of the Parties to the Kyoto Protocol respecting the development of guidelines relating to compliance and the various "flexibility mechanisms". Even where these decisions are made through consensus, they are not subject to domestic democratic scrutiny through ratification procedures, but rather concentrate that authority in the hands of the executive branch of each state. This raises particular concerns for environmentally vulnerable minorities, such as aboriginal peoples, whose views may be inadequately represented in mainstream domestic politics.

Democratic accountability is further eroded by the resort to less formal forms of international environmental regulation through transgovernmental networks, private standard creation bodies and epistemic communities. ${ }^{7}$ While these bodies rarely possess formal regulatory authority, they are able to develop influential policy instruments and affect formal policy creation processes by identifying issues, shaping agendas and controlling information. ${ }^{8}$ The exclusivity of these groups suggests an elitist and technocratic form of governance. The tendency towards expert-dominated decision-making is particularly acute in science-driven areas of regulation, such as environmental law. Here, because the influence of scientific knowledge is linked to credibility, scientific communities impose strict rules about the kind of information that should qualify as scientific. For example, the requirements for reproducible scientific results and high degree of certainty serve to limit participation to those with highly specialised expertise and technical skills and may reject outof-hand views based on alternative methods, such as traditional knowledge maintained by indigenous communities. The price of credibility among a dominant community may be a lack of legitimacy from the perspective of other affected groups. ${ }^{9}$

Part of the challenge facing transnational environmental governance structures is that there exists a tension between different forms of legitimacy. The move away from specific consent was motivated by demands for increased effectiveness, or substantive legitimacy, in environmental rulemaking beyond the state. While the ability of an arrangement to address an identified problem should enhance the legitimacy of that arrangement, substantive legitimacy is premised on a shared

5 Cartagena Protocol on Biosafety to the Convention on Biological Diversity (29 January 2000) 39 ILM 1027.

6 Kyoto Protocol to the United Nations Framework Convention on Climate Change (11 December 1997) 37 ILM 22 [Kyoto Protocol].

7 Discussed in Anne-Marie Slaughter A New World Order (Princeton University Press, Princeton, 2004 ) ch 2.

8 Kal Raustiala "The Architecture of International Cooperation: Transgovernmental Networks and the Future of International Law" (2002) 43 Va J Int'l L 1, 44.

9 See William Clark and others "Information as Influence: How Institutions Mediate the Impact of Scientific Assessments on Global Environmental Affairs" (Harvard University Faculty Research Working Papers Series, Kennedy School of Government, Cambridge (Mass), 2002). 
agreement on the ends sought. In the context of environmental problems, it is clear that reliance on substantive legitimacy alone is inadequate in light of the contested nature of many environmental goals. Reliance on expertise as a basis for legitimacy is similarly constrained in that it too is predicated on pre-existing agreement about substantive values. ${ }^{10}$ Tension also arises in attempts to democratise expert-driven processes since requiring experts to be responsive to political considerations may be viewed as compromising their objectivity. ${ }^{11}$ The point is that careful consideration must be given to structuring different forms of legitimacy in ways that reinforce, or at least minimise, the potential of forms of legitimacy to undercut one another.

The presence of a plurality of views of environmental goals suggests that in any single decision, there will be winners and losers, but if legitimacy is to be maintained, those whose views are not vindicated must be given sufficient reasons to abide by the decision and to continue to engage in subsequent policy processes. As the locus of authority shifts away from domestic institutions and out of the hands of democratically accountable representatives, alternative bases of legitimacy must be found for transnational governance structures. Substantive and expert legitimacy are necessary, but not sufficient, conditions to justify environmental rules. Instead what are required are forms of procedural legitimacy that are less tied to existing political structures and territorial boundaries.

\section{THE THEORETICAL PROMISE OF DELIBERATIVE DEMOCRACY}

The prevailing approach to legitimacy, rooted in liberal individualism, is to aggregate preferences in ways that are acceptable to the participants. Fundamental to aggregative approaches is that actor preferences are taken as fixed and not in need of justification. ${ }^{12}$ Because no one set of substantive preferences can be privileged, aggregative approaches focus on providing fair mechanisms by which different preferences can compete. In order for aggregative methods to be acceptable to minorities, decision-making processes must provide certain minimal assurances. In liberal democracies, these assurances take the form of basic rights and the rule of law. Some of these rights, such as free speech and free association, are necessary to ensure the fair aggregation of preferences, while others are derived from the liberal conception of the individual as free and autonomous. There are, of course, tensions between liberal values and pure democratic values that arise when the popular will clashes with personal freedoms. However, in both cases, legitimacy is maintained because of a shared commitment to the rules of the game. This, in turn, requires a strong sense of political solidarity. In the case of popular democracy, social solidarity is the basis upon which minorities are content to subordinate their interests to the majority. And in the case of

10 Bodansky, above $\mathrm{n} 1$.

11 David Cash and others "Salience, Credibility, Legitimacy and Boundaries: Linking Research, Assessment and Decision Making" (Harvard University Faculty Research Working Papers Series, Kennedy School of Government, Cambridge (Mass), 2002).

12 Gutmann and Thompson, above n 3, 13. 
liberalism, social solidarity is replaced with a kind of procedural solidarity in the form of a common commitment to individual rights and freedoms. Decisions in aggregative approaches are therefore justified on the basis of the method of aggregation, but not on the basis of the preferences themselves, which remain pre-political and not subject to being questioned.

Deliberative democracy proceeds from the opposing premise: that individual preferences are not fixed or exogenous to political interactions and should therefore be justified through the reciprocal giving of reasons for policy choices. Deliberation over policy decisions should be conducted in public forums and on the basis of reasons that may be accepted as fair and reasonable by the other participants. ${ }^{13}$ Like aggregative models, deliberative approaches accept that within any political community there will be a plurality of interests and that very often disagreements over policy will be reasonable. ${ }^{14}$ While aggregative models tend to leave contested policy determinations to be resolved by bargaining power, deliberation requires that participants and decision-makers be open to persuasion based on the power of the arguments provided. ${ }^{15}$ Being open to persuasion does not mean that participants need to surrender their self-interest, but it does require participants to make genuine attempts to arrive at outcomes that are acceptable to the public. Participants in deliberative processes are entitled, at a minimum, to have their views accounted for and responded to. By requiring participants to treat each other's position with a minimum level of respect, deliberative approaches seek to promote the acceptability of decisions taken to all participants.

Conceptions of deliberative democracy differ between theorists, with some theorists, notably Habermas, emphasising the combining of a highly proceduralised view of legitimacy with stringent conditions for successful deliberation, including outcomes based solely on rational agreement. In contrast, Amy Gutmann and Dennis Thompson have offered more of a working theory of deliberation. Gutmann and Thompson maintain that consensus decision-making is neither necessary nor desirable for successful deliberation to occur. In order for decisions to be justified it is not necessary (nor possible), argue Gutmann and Thompson, for members of a community to reconcile deep differences and come to agreement on a comprehensive common good for the same reasons. It is enough that the reasons given be sufficiently convincing to maintain the continued participation of all members. ${ }^{16}$ Their position is premised on the presence of pervasive cultural diversity within democratic communities and a belief that attempts to create an overarching common good would likely be hegemonic. ${ }^{17}$ Accepting pluralism as a social fact does not negate the possibility of

13 Ibid, 3 .

14 Ibid, 14.

15 Simone Chambers "Deliberative Democracy Theory" (2003) 6 Annual Review of Political Science 307, 309.

16 Gutmann and Thompson, above n 4, 26-29. See also Smith, above n 2, 59-60.

17 Ibid, 28-29. 
persuasion and reasonable agreement on important policy concerns. ${ }^{18}$ It does, however, require that members of a political community seek in good faith to put forward reasons that minimise social divisions. ${ }^{19}$

A further area of controversy for deliberate democratic theorists is the extent to which deliberate democratic theory should be concerned with substantive legitimacy. The objection to substantive legitimacy stems from liberal concerns over imposing an unshared vision of substantive justice contrary to the popular will. Proceduralism is justified on the basis of its neutrality and consistency with human autonomy and freedom. However, Gutmann and Thompson argue that assessing the legitimacy of outcomes based on adherence to procedural requirements cannot be neatly separated from substantive criteria. ${ }^{20}$

Treating either procedural or substantive norms as foundational and therefore, not subject to the requirement of prior justification, risks undermining the democratic nature of deliberation as an approach to governance. Gutmann and Thompson avoid this problem by maintaining that procedural, as well as substantive, criteria are provisional in nature and should be open to contestation on reasoned grounds. Provisionality does not equate to continual deliberation, but only requires that rules be subject to deliberation at some time and that they be open for reconsideration in the future. Once a norm has achieved widespread legitimacy within in a community, there is no moral requirement for deliberation. This does not mean that the norm may be not need to be reconsidered in light of changed circumstances. ${ }^{21}$

Because aggregative models must define political communities with reference to formal criteria (in order to know whose preferences are being aggregated), they do not translate well to the transnational sphere where political communities tend to be fluid and overlapping, consisting of a wide number of different actors that are responsible to different communities and interests. ${ }^{22}$ Deliberative democracy addresses this problem by locating legitimacy in the deliberative process itself. It is the quality of political interaction between interested parties that determines the legitimacy of the outcome, as opposed to the method of aggregation. By understanding legitimacy as being determined by the quality of reasons being put forward and the reciprocal nature of

18 But see Walter F Baber and Robert V Bartlett Deliberative Environmental Politics: Democracy and Environmental Rationality (MIT Press, Cambridge (Mass), 2005) 108-111.

19 What Gutmann and Thompson, above n 3, refer to as "economising on moral disagreement."

20 Ibid, 25

21 Ibid, 117

22 Dennis Thompson "Democratic Theory and Global Society" (1999) 7 J of Political Philosophy 111, 112, refers to this as the "problem of many majorities." See also Nico Krisch "The Pluralism of Global Administrative Law" (2006) 17 EJIL 247, discussing multiple constituencies. 
justification, deliberative models expand the scope of political accountability. ${ }^{23}$ Whereas representative models tend to define accountability in terms of formal membership criteria, deliberative models link accountability to affectedness. ${ }^{24}$

Consider, for example, the problem of transboundary pollution. A state from which pollution originates under a representative model is only accountable to voters within the source state. Those voters may favour pollution because they do not suffer its ill effects and they reap the benefits of increased economic activity. A deliberative model maintains that the decision to pollute must be justified to both electors and to affected members of the receiving state. Here the legitimacy of the decision depends on the reciprocal nature of the justifications given and the consideration given to the position of those affected, who must in turn express their reasons in reciprocal terms. The interactions are not restricted to actors who hold a formal right pursuant to international legal rules and so would include affected individuals and sub-state actors. Because participation in deliberative processes is not defined by formal criteria, the reasons given will not be oriented towards satisfying narrow interests, but will be oriented towards outcomes that take into account the public's interests.

A related challenge that arises from the fluidity of community membership in the transnational context is the likelihood that participants will not constitute a 'demos', at least as understood traditionally. As noted above, aggregative models of democracy rely on the presence of a shared commitment to substantive or procedural values among community members, which is arguably absent in the transnational sphere. ${ }^{25}$ Unquestionably, deliberative approaches require participants to be able to establish a shared basis of reciprocity. In other words, participants must be able to recognise that justifications are publicly oriented. This does not, however, necessitate the presence of a thickly constituted political community that has a common history or political culture. Deliberative democracy, as understood by Gutmann and Thompson, requires only a shared commitment to the principle that binding decisions should be justified by moral or principled reasons. ${ }^{26}$ Beyond this basic principle, communities are free to determine both the procedural and substantive bases of their justificatory processes. Persuasion is possible because self-governing groups can come to agree upon principles upon which future decisions will be justified. These principles are provisional, but so long as they are themselves accepted as being justified, they can form the basis of future deliberations.

23 Ibid, 120

24 Gutmann and Thompson refer to those affected as "moral constituents."

25 See Anthony McGrew "Transnational democracy" in April Carter and Geoffrey Stokes (eds) Democratic Theory Today: Challenges for the 21st Century (Polity Press, Cambridge (Mass), 2002) 269. See also J H H Weiler "The Geology of International Law - Governance, Democracy and Legitimacy" (2004) 64 SaöRV 547.

26 Gutmann and Thompson, above n 6, 114. 
In the context of transnational environmental governance, accepting the presence of deep and enduring disagreements over values is prudent in light of the deep divisions between developed and developing countries over responsibility for global environmental harm and approaches to global environmental governance. ${ }^{27}$ Accepting that core beliefs over the extent of the right to development will continue to be contested and must therefore be subject to deliberation finds the middle ground between the hegemonic imposition of values that are perceived as being favourable to developed countries' interests and a purely voluntaristic approach based on unmitigated state sovereignty. Developed and developing countries may have similarly irreconcilable differences regarding environmental and economic interests.

A further source of concern is the impact that deliberation will have on efficient decisionmaking. The requirement for inclusivity would appear likely to increase decision-making costs. These costs may be exacerbated by the need for decision-makers to determine stakeholders in relation to different decisions and to ensure that diffuse interests and vulnerable groups are included in deliberations. The process of deliberation itself can be demanding, requiring the dissemination of complex, often technical, information to large groups and requiring opportunities for participants to respond to one another. These demands are compounded in a transnational context where language differences, geographical remoteness and vastly divergent capacities to effectively participate will impact upon deliberative processes. Finally, provisionality suggests that decisions may be revisited which raises concerns about finality and stability within a policy creation framework.

Deliberative democratic theorists have several responses to efficiency critiques. Firstly, deliberative processes do not require consensus and therefore will need to be supplemented by other forms of decision-making. These other forms of decision-making can bring finality and certainty to policy processes. ${ }^{28}$ Secondly, because deliberative processes seek to promote legitimacy through accountability, at a practical level deliberative processes do not require the creation of new institutions and forums, but rather the intention is to ensure that existing interactions are justificatory in nature. Finally, provisionality need not result in instability, but can in fact be built into policy processes in a predictable manner. In an environmental context, where scientific knowledge and technical responses to environmental change are constantly evolving, providing for orderly change through adaptive management is recognised as a fundamental organising principle of policy creation. $^{29}$

27 See Obijiofor Aginam "Saving the Tortoise, the Turtle, and the Terrapin: The Hegemony of Global Environmentalism and the Marginalisation of Third World Approaches to Sustainable Development" in Obiora Okafor and Obijiofor Aginam (eds) Humanising Our Global Order: Essays in Honour of Ivan Head (University of Toronto Press, Toronto, 2003) 12.

28 Gutmann and Thompson, above n 3, 18 .

29 See Kai Lee "Appraising Adaptive Management" in John S Drysek and David Schlosberg (eds) Debating the Earth: The Environmental Politics Reader (2 ed, Oxford University Press, New York, 2005) 104. 
Deliberative approaches also appear well suited to address legitimacy concerns related to the role of science in transnational environmental policy-making. The use of experts to legitimise policy processes is dependent on the legitimacy of those processes themselves. While legitimacy is clearly derived in part from the qualifications of experts, this necessarily exclusionary practice creates tensions of its own. The difficulty here is that aggregative approaches to democratic decision-making, such as voting, are not readily transferable to expert inquiry. Moreover, the principal justification for expert authority in aggregative models relies heavily on qualifications and on a separation between values and empirical knowledge. But both are contested. Deliberative models suggest a rejection of a bright line division between science and non-science on some a priori basis and would subject those boundaries to deliberation. Deliberative theories would also subject the basis of qualification to deliberation. ${ }^{30}$ A prominent example of this is the explicit recognition of traditional knowledge as a source of valid scientific knowledge, notwithstanding its failure to adhere to the positivistic scientific methodology that prevails in the scientific community. ${ }^{31}$ Perhaps most importantly deliberative models would not exempt scientists and other experts from the requirement of justifying their positions in a principled and public fashion. This would require expert communities to present their arguments in ways that are accessible to lay participants. Requiring experts to engage in deliberative processes which may question fundamental methodological and empirical assumptions may also address power differentials between experts and lay people by recognising the inherently contingent and bounded nature of scientific knowledge. ${ }^{32}$

Despite the attractiveness of deliberative democratic theory in alleviating legitimacy concerns in transnational environmental governance structures, there remain serious questions regarding the practical application of deliberative approaches to actual policy processes. There is an abstract quality around the debate regarding the democratisation of the transnational sphere as little attention has been paid to existing institutional mechanisms that promote deliberation. Among the outstanding questions are the following: how might deliberative processes determine membership of a particular deliberative community; how can transnational decision-making processes be structured to promote transparent, discursive, and principled deliberations; are there mechanisms available for sanctioning decision-makers who fail to adequately justify their decisions; how can deliberative processes interact with scientific practices; and finally, can the requirement for mutual respect (which would seem to require participants to genuinely consider the arguments of others) be put into operation?

30 Karin Bäckstrand "Civic Science for Sustainability: Reframing the Role of Experts, Policy-Makers and Citisens in Environmental Governance" (2003) 3:4 Global Envt'l Politics 24, 33-34. See also Baber and Bartlett, above n 18, 186-92.

31 See Convention on Biological Diversity (5 June 1992) 1760 UNTS 79; 31 ILM 818 [CBD].

32 Bäckstrand, above n 30, 34 . 
As a way to address some of these outstanding questions and to answer the larger, implicit question as to the practical feasibility of implementing deliberative democratic processes in transnational environmental governance structures, the final part of this paper examines the structure and role of environmental impact assessments (EIAs) in transnational environmental governance. International commitments to conduct EIAs, their sources and their implementation are discussed with a view to assessing whether EIAs possess characteristics that promote principled deliberation over environmental issues in transnational settings. Particular consideration is given to how EIAs can enhance the legitimacy of policy decisions in transnational governance structures.

\section{ENVIRONMENTAL IMPACT ASSESSMENTS AS DELIBERATIVE MECHANISMS}

As an approach to environmental decision-making, EIAs are unique in that they do not require adherence to a predetermined environmental outcome, but rather they require decision-makers to account for environmental values in their decisions and to justify those decisions in light of detailed environmental studies and public comments on the potential environmental impacts of the proposal. ${ }^{33}$ The process is self-regulatory in that decision-makers are not required to abandon environmentally harmful activities or even mitigate predicted environmental harms. Instead, EIA obligations require adherence to a detailed set of procedural requirements aimed at ensuring that the environmental consequences of decisions are fully explored and that those affected have an opportunity to participate in the decision-making process. The principal vehicle for assessment and consultation is an environmental impact statement or report. In carrying out the assessment, the decision-maker (in most domestic systems, this is the government agency responsible for the undertaking whose environmental impact is being considered) must consider the impacts of both the undertaking itself, and the impacts of a range of alternatives to the undertaking. The EIA report forms the basis of consultation with other affected agencies and with the public. Despite not requiring decision-makers to avoid environmentally harmful activities or to choose the least harmful alternative, EIA processes are not ambivalent about the kinds of values and principles decisionsmakers should account for in arriving at their decisions. The essential structure of EIA processes is a combination of well defined procedural rules coupled with a strong statement of environmental values, which despite being open-ended, is clearly meant to influence outcomes by requiring decision-makers to publicly account for those values and justify their decisions in light of them.

As an approach to international policy creation, EIAs have been adopted across a broad spectrum of issue areas and institutional contexts. Most prominent are transboundary EIA obligations such as those contained in the Convention on Environmental Impact Assessment in a

33 There are numerous accounts of the nature of EIA processes. A good starting point is Jane Holder Environmental Assessment: The Regulation of Decision Making (Oxford University Press, New York, 2004) ch 1. For a comparative discussion of the elements of various domestic EIA systems, see Christopher Wood Environmental Impact Assessment: A Comparative Review (2 ed, Prentice Hall, Harlow, 2002). 
Transboundary Context (the Espoo Convention), ${ }^{34}$ and the European Community Directive on EIAs (the EIA Directive). ${ }^{35}$ Obligations to conduct EIAs reflect existing customary obligations to prevent transboundary harm and to cooperate with potentially impacted states through notification and consultation of potential impacts. ${ }^{36}$ Issues impacting the global commons are also the subject of EIA obligations. The Antarctic Protocol, which governs the "comprehensive protection" of the Antarctic environment includes detailed EIA obligations, addresses virtually all human activities conducted within the Antarctic. ${ }^{37}$ Similarly, the United Nations Convention on the Law of the Sea (UNCLOS) requires states to conduct EIAs where planned activities under their control may cause significant environmental impacts to the marine environment. ${ }^{38}$ A final set of international environmental issues that make use of EIA processes are issues of global common concern, such as biological diversity and climate change. Unlike transboundary or global commons impacts, issues of common concern impact other states less directly in that the impacts themselves may be purely domestic or diffusely distributed. Nevertheless, international agreements place obligations on states to assess project impacts on biological diversity or climate change in recognition of the universal character of the problem itself. ${ }^{39}$

Most international EIA commitments contemplate that the implementation of international obligations will occur through domestic EIA processes, as opposed to a distinct international process. Transboundary obligations are implemented by extending assessment, notification and consultation requirements beyond the state. For example, those responsible for carrying out EIAs are required to assess impacts to the environment without regard for national boundaries, and to engage foreign agencies and foreign members of the public on the same basis as domestic agencies and citizens. International agreements on transboundary EIAs ensure reciprocity between states by imposing minimum standards for transboundary EIAs. In a similar fashion, EIA commitments in

34 Convention on Environmental Impact Assessment in a Transboundary Context (25 February 1991) 1989 UNTS 309; 30 ILM 802 [Espoo Convention].

35 Council Directive (EC) 85/337 On the Assessment of the Effects of Certain Public and Private Projects on the Environment [1985] OJ L175/40, as amended by Council Directive (EC) 97/11 [1997] OJ L73/5 and Council Directive (EC) 03/35.

36 For a discussion of relationship between the harm principle, the duty to cooperate and EIAs, see Günther Handl "Environmental Security and Global Change: The Challenge to International Law" (1990) 1 YB Int'l Env L 3. But see John Knox "The Myth and Reality of Transboundary Environmental Impact Assessment" (2002) 96 Am J Int'1 L 291.

37 See the Protocol to the Antarctic Treaty on Environmental Protection (4 October 1991) 30 ILM 1461, art 8 and Annex 1 [Antarctic Protocol].

38 See United Nations Convention on the Law of the Sea (10 December 1982) 1833 UNTS 3; 21 ILM 1261, art 8 and Annex 1 [UNCLOS].

39 CBD, above n 31, Art 14; United Nations Framework Convention on Climate Change (9 May 1992) 1771 UNTS 107; 31 ILM 849, art 4(1)(f). 
the Convention on Biological Diversity (CBD) require states to ensure that domestic EIA processes consider the impacts of planned activities on all levels of biological diversity. Despite being an entirely domestic process, the resulting interactions are transnational in the sense that the CBD requires deliberation over the applicability of internationally generated environmental norms in specific domestic contexts.

International institutions may also employ EIA process in their own decision-making processes. Here the most developed example is the use of EIA processes by the World Bank and other international development banks to ensure that bank-financed activities are "environmentally sound and sustainable". 40 The World Bank requirements demand consideration of local, transboundary and global environmental issues and include requirements for extensive public consultation. The interactions are not state-to-state or state-to-individual, but rather involve interactions between international organisations, affected states and affected members of the public regarding acceptable levels of environmental impact. An emerging area of EIA application in the transnational sphere is their use by treaty bodies in internal decision-making procedures, such as the EIA requirements as a condition of approval for projects under the Clean Development Mechanism in the climate change regime. ${ }^{41}$

The varying scope and institutional settings of EIA commitments reflects the diversity of problem structures into which EIA processes are pressed into service. But despite this diversity, the core structure of EIA processes is retained at the transnational level. At its heart is the use of open and discursive interactions over specific policy decisions into which the substantive goals of the particular environmental regime are projected. The substantive goals tend to be abstracted to the level of principle, but the contextualised nature of their application in relation to specific projects allows potentially affected groups to interpret and elaborate on the meaning of international environmental principles, such as the harm principle, the protection of biodiversity or of unique and fragile ecosystems, in relation to a specific factual basis. Because the elaboration of environmental principles is difficult in the abstract, EIA processes substitute procedural specificity for substantive specificity - seeking to create an information-rich and inclusive decision-making environment. From a deliberative aspect, the efficacy of EIAs in holding decision-makers to account is dependent on the ability of EIAs to promote policy processes that are inclusive, information rich, discursive, principled and provisional.

40 World Bank Operational Policies - Environmental Assessment (Operational Directive OP 4.01, World Bank, Washington, 1999) [OP 4.01]; World Bank Banking Procedures - Environmental Assessment (Bank Procedures BP 4.01, World Bank, Washington, 1999) [BP 4.01] www.worldbank.org/legal/ (accessed 1 January 2007).

41 United Nations Framework Convention on Climate Change "Modalities and Procedures for a Clean Development Mechanism defined by Art 12 of the Kyoto Protocol" Draft Decision FCCC/CP/2001/13/Add 2, Annex, s 37 . 


\section{A INCLUSIVITY}

International EIA commitments address two challenges to determining the extent of deliberative involvement in transnational environmental decisions. Firstly, EIAs determine membership on the basis of affectedness, not formal legal criteria, and in this regard, EIA commitments extend obligations to notify and consult beyond national boundaries and across the public/private divide. For example, the Espoo Convention provides that participation not be restricted to state parties, but should also include members of the public within the affected state. Consequently, even where the affected state may not have concerns regarding transboundary impacts, there remains an opportunity for affected individuals and groups to participate in the decision-making process. Other transnational EIA processes, notably the Arctic EIA Guidelines, explicitly recognise the vulnerability of indigenous groups to environmental change and provide specific strategies for ensuring the participation of these groups in EIA processes. ${ }^{42}$ The World Bank's EIA process goes even further in that its procedures not only require broad-based participation, but extend rights of review to individuals through the Inspection Panel process. ${ }^{43}$

Secondly, EIA processes identify a common standard for determining affectedness - likelihood of "significant adverse transboundary impact". 44 "Significance" as a threshold is not by itself a particularly helpful criteria. However, international instruments have adopted a variety of methods to further refine the "significance" threshold. For example, the United Nations Environment Programme Goals and Principles of Environmental Impact Assessment indicate that states should categorise certain activities, geographic areas or resources that are likely to give rise to significant impacts. The Espoo Convention makes use of this approach by listing activities that are required to be subject to an initial determination of significance and by providing a further list of criteria by which significance can be determined. ${ }^{45}$ The CBD EIA Guidelines provide a further set of screening criteria related specifically to determining significance in relation to impacts on biodiversity.

42 Finnish Ministry of the Environment Guidelines for Environmental Impact Assessment in the Arctic (Finnish Ministry of the Environment, Helsinki, 1997) 37, adopted by the Arctic Council in the Alta Declaration on the Protection of the Arctic Environmental Protection Strategy [Arctic EIA Guidelines]. See also, Conference of the Parties to the Convention on Biological Diversity "Guidelines for Incorporating Biodiversity-related Issues into Environmental Impact Assessment Legislation and/or Processes and in Strategic Environmental Assessment" (14 February 2002) UNEP/CBD/COP/6/7, Annex, para 28 ["CBD EIA Guidelines"] recognising the importance of including minority groups in participation.

43 See World Bank Resolution No IRBD 93-10; World Bank Resolution No IDA 93-6, creating the Inspection Panel in 1993.

44 Espoo Convention, above n 34, art 2.

45 Ibid, Appendix I and Appendix III. 


\section{B Information Rich}

The deliberative quality of any policy process is highly dependent upon the quality of information available to the participants. To this end, all EIA processes prescribe specific and rigorous minimum requirements for EIA documentation and require that this information be exchanged in advance of consultations. ${ }^{46}$ In the transboundary context, a difficulty lies with the fact that often it is the affected state that is in possession of the best baseline environment information respecting their domestic environment. Consequently, the Espoo Convention provides not only obligations on the source state to provide information, but also on the affected state to provide "reasonably obtainable information" at the request of the source state.

A further challenge to the successful incorporation of scientific knowledge into policy processes is ensuring that the information that is the subject of policy deliberations is credible to the participants and salient to the policy problem under deliberation. ${ }^{47}$ Exposing the scientific analysis underlying an EIA to public scrutiny provides reassurance that the scientific methods and analysis used by the project proponent are sound and may be reasonably relied upon. This credibilityenhancing role is furthered by rules requiring the EIA documents to be accompanied by a nontechnical summary. The requirement that the information subject to deliberation be in a publicly accessible form is integral to the deliberative process.

The explicit recognition of specific types of knowledge as being germane to EIA processes, particularly traditional knowledge that may not otherwise be represented in the scientific process, also enhances the credibility of the factual basis upon which decisions are made by ensuring that a particular community's knowledge is not marginalised. EIA processes also seek to ensure the salience of scientific information through an iterative and participatory process for determining the scope of environmental impact studies, although international EIA commitments, such as the Espoo Convention and the Antarctic Protocol, fall short of requiring public consultation prior to the completion of the EIA document. ${ }^{48}$ By subjecting the actual EIA report to deliberation, EIA processes provide opportunity for reflection over scientific norms.

\section{Discursiveness}

The iterative nature of EIA processes varies, but where the screening and scoping requirements include consultation, the result is that affected states are involved in identifying the environmental issues and the alternatives to the proposal. Even in cases where public consultation is limited to reviewing a draft EIA report and providing comments, the structure retains a discursive element because the interested parties still have an ability to provide comments on the EIA to which the state

46 See, for example, Ibid, Appendix II.

47 See Cash and others, above $\mathrm{n} 11$.

48 Espoo Convention, above n 34, arts 3(1), 4(1); Antarctic Protocol, above n 37, Annex 1, arts 3(3)-(6). 
of origin is required to respond. ${ }^{49}$ Under the Espoo Convention, it is expressly contemplated that the parties shall enter into consultations, in effect mandating that the legitimate concerns of affected parties cannot be ignored. ${ }^{50}$

EIA processes respond to the need for desirable deliberative conditions in a number of ways. Firstly, the requirement to examine alternatives tends to sharpen the discourse over appropriate outcomes. Alternatives help create contradictions by demonstrating that project objectives can be achieved in ways that better adhere to environmental values. These contradictions can, in turn, be exploited to generate reflection and change. Secondly, EIA processes are generally oriented toward government decision-making. ${ }^{51}$ This is not to say that a private project will not be subject to EIAs, but usually only where those projects require government approval. Government decision-makers are subject to unique constraints that promote decision-making that takes into account the public interest; they are repeat participants in deliberative processes and are both generators and recipients of environmental harm. Transboundary EIA processes are underlaid by a broad principle of nondiscrimination that requires states to treat environmental impacts on areas outside its jurisdiction no differently from those impacts that occur within its jurisdiction. ${ }^{52}$ As repeat participants it will be more difficult for states and state agencies to hold contradictory positions depending on the nature of their interest in a particular EIA process. ${ }^{53}$ Thus, EIA processes are oriented towards promoting public-regarding behaviour from those actors most inclined to behave cooperatively. The requirement of genuineness suggests that a state that proposes a planned activity must consider objections with an open mind and on a principled basis. From a more instrumental standpoint, as repeat participants in a highly interdependent environment, states, and indeed other transnational actors, will be concerned with their community standing. Thus, failure to act in good faith may have negative reputational consequences.

\section{Principled}

Assessing good faith necessarily involves a consideration of the adequacy of the reasons given for a decision. This, in turn, points to the importance of shared substantive norms to the deliberative process, as substantive norms will form the shared basis upon which the rationality of reasons and decisions are judged. Gutmann and Thompson argue that deliberative outcomes are more likely to be accepted as legitimate where the participants can, at a minimum, accept the reasonableness (or

49 Ibid, Art 6(1) and Annex 1, art 3(6).

50 Ibid, art 5 .

51 In some jurisdictions EIA processes will apply to purely private decision-making. For a comparative discussion of the coverage of EIA processes, see Wood, above $\mathrm{n} 33$, ch 7 .

52 See Knox, above n 36.

53 This point is consistent with game theoretical models that show that repeat participants in Prisoners' Dilemma type games will show a greater tendency towards cooperation than one time participants. 
moral merit) of the decision. ${ }^{54}$ Good faith and reasoned deliberation promote mutually respectful decision-making. It follows that in order for processes to result in legitimate deliberations, they should project norms into deliberative interactions. As discussed earlier, EIA processes are directed towards the achievement of broadly defined environmental goals. In transboundary EIA commitments that end is to prevent transboundary environmental harm. ${ }^{55}$ In the CBD, EIAs are expressly stated to be conducted with the intent of avoiding or minimising significant adverse effects to biological diversity. ${ }^{56}$ The assessment procedures under UNCLOS have as their objective the prevention of marine pollution, while the Antarctic and Arctic regime require EIAs in furtherance of the preservation of the polar ecosystems.

As in domestic EIA systems, the substantive ends to which international EIA commitments are directed are open-ended, raising questions as to whether they can effectively influence choices regarding environmental outcomes. However, in many cases, EIA processes may be able to draw on more precise standards and rules in order to elaborate on more ambiguous principles. For example, the CBD EIA Guidelines cite resources identified in both the Ramsar Convention on Wetlands of International Importance ${ }^{57}$ and the Convention on Migratory Species ${ }^{58}$ as being a basis by which states can make screening decisions. ${ }^{59}$ The intended result is that the requirements of these conventions are implemented in domestic legislation by ensuring that activities undertaken do not have adverse impacts on the resources that are the subject of the convention, such as a listed wetland under the Ramsar Convention. As an example, the Canadian Environmental Assessment Act (CEAA) clearly anticipates the listing or description of a feature in an international convention will contribute to a determination of significance under CEAA. ${ }^{60}$

A related instance of the integration of pre-existing standards into international EIA processes is the use of these standards in investigating a transboundary impact. For example, in an EIA assessment process relating to an electrical generating facility (the "Sumas 2 Generating Station") in the State of Washington that had air quality impacts on neighbouring British Columbia, the

54 Gutmann and Thompson, above n 3, 11.

55 See Espoo Convention, above n 34, art 2(1).

56 CBD, above n 31, art 14(1).

57 Ramsar Convention on Wetlands of International Importance (2 February 1971) 996 UNTS $245 ; 11$ ILM 963.

58 Convention on Migratory Species (23 June 1979) 19 ILM 15.

59 "CBD EIA Guidelines", above n 42, paras 8-17; Appendices I \& II.

60 Discussed in Pauline Lynch-Stewart Using Ecological Standards, Guidelines and Objectives for Determining Significance: An Examination of Existing Information to Support Decisions Involving Wetlands (CEAA Research and Development Monograph Series, Ottawa, 2000), listing Ramsar, the Migratory Birds Convention and the Canada-United States Great Lakes Water Quality Agreement as ecological benchmarks to determine significance. 
environmental impact statement (EIS) prepared by the proponent considered the impact of the project on air quality on both sides of the Canada-United States border. In so doing, the EIS had regard for United States federal and state air quality regulations and objectives, as well as Canadian, federal and provincial objectives. ${ }^{61}$ The standards referred to here are domestic in origin. Their application elaborates the international obligation to prevent transboundary harm by reference to affected states' air quality standards as a relevant indicator for determining significant harm. Very often recourse is to standards or principles contained in instruments that are not themselves formally binding. This, however, points to a potential strength of EIA processes. Because the use of standards in EIA processes does not result in any formally binding result, the value of these sources is not in their normative status, but rather in their ability to persuade. Take, for example, the use of Canadian-based air quality standards in the Sumas Energy EIS: these standards are in no way binding, but they are clearly persuasive because they indicate levels of acceptable air quality as determined by the authorities of the affected state.

\section{E Provisionality}

Once deliberative participants have come to accept normative and factual propositions as justified, these norms and facts no longer need to be the subject of future deliberation, but instead can become the basis for justification in future deliberations. The form of reasoning that arises is not formal in the sense that outcomes are derived logically from principles and rules. Rather, because norms and facts are contingent and provisional they must be continually reassessed in light of new factual information and competing norms.

Here too EIAs can be seen as institutionalising a critical aspect of deliberative democracy, although in a more emergent fashion. Traditionally, the ex ante and predictive nature of EIAs has been subject to criticism on the basis that it wrongly assumes a fairly complete and accurate scientific understanding of future impacts. ${ }^{62}$ While this criticism clearly retains some bite, EIA procedures in both the domestic and transnational levels have moved towards the recognition of the precarious nature of scientific knowledge through post-project monitoring, adaptive management techniques and through the use of feedback mechanisms.

EIA processes, by retaining the discretion of the decision-maker, ensure that decisions can be carried out despite residual objections. But in recognition of the fallibility of the predictive process, domestic EIA systems are beginning to require that approvals be subject to requirements to conduct some form of "post-project analysis", usually in the form of monitoring. ${ }^{63}$ The inclusion of a weak

61 Washington State Energy Facility Site Evaluation Council Sumas Energy 2 Generating Facility, Final EIS (Olympia, WA, 2001).

62 See Bradley Karkkainen "Toward a Smarter NEPA: Monitoring and Managing Government's Environmental Performance" (2002) 102 Colum L Rev 903, 926.

63 See Wood, above n 33, ch 14 . 
obligation to engage in "post-project analysis" suggests that states may have on-going obligations to ensure that their activities, once constructed and operating, do not cause significant adverse transboundary impacts. ${ }^{64}$

The presence of post-project procedures can promote acceptability of final decisions because on a project-by-project basis, they retain the possibility of future deliberations where environmental impacts exceed predicted levels. Over multiple decisions, where predictive failures are fed into future EIA processes, participants can challenge accepted methods and received scientific knowledge. At present EIA processes fall short of the deliberative ideal, but there is a discernible trend towards incorporating greater provisionality.

\section{CONCLUSION}

In this paper I have argued that states and other actors are likely to face increased pressure to enhance the legitimacy of their decision-making processes as policy authority is transferred from purely domestic to transnational actors and institutions. Fundamental to the legitimacy challenge in transnational environmental governance is adapting forms of accountability to bridge the widening gap between decision-makers and those affected by their decisions. To this end, I have argued that deliberative democratic theory has much promise in addressing legitimacy concerns in transnational environmental governance structures. This is in large measure because deliberative approaches incorporate a more informal legal rationality that is not premised on foundationalist understandings of what constitutes right process or right outcomes. Instead, deliberative models require that political interactions, whether vertical or horizontal, be oriented towards the public justification of decisions through the reciprocal giving of reasons. Deliberative processes were compared with EIAs, an existing form of policy-making in transnational environmental governance structures, with a view to demonstrating that deliberative processes can be successfully and usefully institutionalised in the transnational sphere.

Deliberative approaches are not bound to a territorially defined polity: since the requirement of justification relates in a universal way to political decision-making, they have broad application across different political contexts. The EIA processes discussed demonstrate this point aptly. EIAs are incorporated into state-to-state interactions over transboundary and global commons issues, into the decisions of international organisations and subsidiary bodies within treaty frameworks, and domestically, EIA processes are sites for deliberation over the application of international environmental norms to domestic policy questions. As a corollary, deliberative processes are well suited to the polycentric decisions that characterise environmental policy questions. Again, EIAs are a good demonstration of the ability for policy processes to be structured so as to include a multiplicity of state, sub-state and non-state actors. The membership of the deliberative community is determined on the basis of affectedness, which clearly transcends political boundaries. EIA

64 Espoo Convention, above n 34, art 7. See also Antarctic Protocol, above n 37, art 5. 
requirements, through defining uniform thresholds of affectedness, provide predictability and stability to the deliberative process. Practical difficulties are addressed through the identification of points of contacts in foreign countries, ${ }^{65}$ the use of existing international structures for dissemination of information, ${ }^{66}$ and the identification of environmentally vulnerable communities. ${ }^{67}$

The application of democratic theory to transnational governance by scholars has been questioned on the basis that there is no international or transnational demos. ${ }^{68}$ I make no claims of resolving this difficulty here, but I have argued that the deliberative approach of Gutmann and Thompson provides a sound theoretical basis for democratising existing transnational environmental governance structures. Importantly, Gutmann and Thompson accept the presence of deep divisions over moral issues as an enduring social fact, as is the unequal distribution of material wealth. Both of these systems characteristics are present and must be accounted for in transnational environmental governance.

In light of pervasive disagreement, Gutmann and Thompson argue that an important democratic goal is providing members of a political community with sufficient justification for authoritative decisions to ensure their continued participation in future decision-making processes. Transnational EIA processes provide insights into how this justificatory process can be put into operation beyond the state. At the heart of the EIA process is an elaborate set of procedural requirements aimed at promoting deliberation over both facts and norms in relation to a known context. EIA processes, by requiring decision-makers to account for environmental values and to justify their decisions in light of those values, seek to promote principled policy-making. Because these environmental values arise from existing commitments they represent at least some provisional agreement at a principled level over environmental ends sought. However, the EIA process requires deliberation over the norm's application to the specific decision, providing an opportunity for both further contestation and solidification of the norm within the deliberative community. Provisionality applies equally to facts and, to this end, EIA processes again show how expert knowledge can be both projected into policy processes, allowing decision-makers to derive legitimacy from the impartiality and specialised knowledge of experts without unduly sacrificing the credibility and salience of that scientific knowledge.

To be clear, I do not seek to hold out EIA processes as a panacea to legitimacy concerns in transnational environmental governance. Indeed, my analysis suggests some clear limitations to the use of EIAs. For example, the requirement for context makes EIAs well suited to policy decisions

65 Espoo Convention, above n 34, art 3.

66 Antarctic Protocol, above n 37, Annex 1 (requiring the circulation of EIA documentation to Committee on Environmental Protection of the Antarctic Consultative Meeting).

67 Arctic EIA Guidelines, above n 42; CBD, above n 31. 
respecting physical projects for which a high degree of detail can be determined, but makes it is less well suited to decisions regarding policies and programmes. ${ }^{69}$ However, very often programmatic decisions, for example regarding energy policy, may severely limit the possible range of alternatives at the project level. Deliberative theory suggests that language differences among participants, literacy levels and communication infrastructure will be important factors in determining the success of EIAs. Finally, there is no reason to think that EIA processes will not be subject to the same substantive legitimacy problems affecting other forms of environmental decision-making arising from efficiency problems. ${ }^{70}$

My central argument however is more modest. Legitimacy in environmental decision-making takes a number of forms - I have focused on procedural, substantive and expert legitimacy. The success of EIA processes in generating legitimate decisions is in their ability to draw upon and structure these different forms of legitimacy. In recognising the limitations of process, shared environmental goals and science on their own to bring about legitimate decisions, EIAs recognise the fluid boundaries between these forms of legitimacy and bring each to bear on the other. The adoption of this policy strategy within an increasing number of transnational contexts suggests that deliberative democratic processes can usefully inform institutional design to enhance the legitimacy of environmental decision-making beyond the state.

69 In this regard, the need for contextualised decision-making calls into question the effectiveness of strategic environmental assessment, which looks at the environmental impacts of policies, plans and programmes.

70 It must be noted that EIA policy makers and practitioners are aware of these shortcomings and continue to address them. See, for example, United States Council on Environmental Quality The National Environmental Policy Act: A Study of its Effectiveness After Twenty-five Years (United States Council on Environmental Quality, Washington, 1997) 31. 
